\title{
DETERMINANTES DA ENTRADA DE TURISTAS ESTRANGEIROS NOS ESTADOS BRASILEIROS NO PERIODO 2004 A 2008: UMA ABORGAGEM COM $O$ MODELO GRAVITACIONAL DO TURISMO
}

\author{
Magnus dos Reis' \\ Jacqueline Lopes Nunes ${ }^{2}$ \\ Camila Flores Orth ${ }^{3}$ \\ Marcos Tadeu Caputi Lélis ${ }^{4}$
}

\begin{abstract}
Resumo
O turismo é uma atividade econômica importante para os países, pois uma expansão deste setor permite aumentar o PIB, alavancar investimentos, gerar emprego e atrair divisas. Nos últimos anos, este setor tem ganhado importância na economia brasileira, uma vez que há um aumento significativo da entrada de turistas estrangeiros no país. Para os próximos anos, devido à realização da Copa do Mundo de 2014 e das Olimpíadas do Rio de Janeiro em 2016, a entrada de turistas estrangeiros no país aumentará consideravelmente. Nesse sentido, torna-se fundamental que o setor público e privado compreendam os determinantes dos fluxos turísticos ao país, visando estabelecer estratégias para atrair visitantes. Para isso, foi proposta uma forma alternativa de estimação do modelo gravitacional, através de um modelo hierárquico em dois níveis, tendo como $1^{\mathrm{o}}$ nível a equação gravitacional com dados em painel e dois efeitos fixos e, no $2^{\circ}$ nível, uma regressão em cross-section. O resultado mais surpreendente desta análise foi que o estado de São Paulo apresentou um dos menores índices de atratividades de lazer dos estados analisados. Entretanto, São Paulo é o estado que mais recebeu turistas estrangeiros do país. A aparente contradição é explicada pelo fato de que São Paulo possui
\end{abstract}

\footnotetext{
Mestre em Economia pela Universidade do Vale do Rio dos Sinos - UNISINOS.

Mestre em Economia pela Universidade do Vale do Rio dos Sinos - UNISINOS.

Mestranda em Economia pela Universidade do Vale do Rio dos Sinos - UNISINOS.

Professor da UNISINOS e Coordenador da Unidade de Inteligência Comercial e Competitiva da PEX-Brasil.
} 
Determinantes da entrada de turistas estrangeiros nos estados brasileiros no período 2004 a 2008:

uma aborgagem com o modelo gravitacional do turismo

o maior PIB do país, ou seja, apresenta a maior atratividade de negócios. Portanto, esse resultado sugere que os turistas estrangeiros que vão a São Paulo estão em busca de negócios e não de lazer.

Palavras-chave: Fluxos turísticos; Modelo Gravitacional; Dados em painel.

Classificação JEL: L83; C23; C21.

\section{INTRODUÇÃO}

O Brasil é conhecido por sua extensa área territorial, de aproximadamente 8,5 milhões de $\mathrm{km}^{2}$, que engloba 26 Estados e o Distrito Federal. Esta característica permite que o país ofereça belezas naturais e clima diferenciados. São essas propriedades geográficas peculiares que possibilitam o país, de certa forma, ter um grande potencial de atrativos de lazer para os turistas, tanto estrangeiros quanto brasileiros. Os dados corroboram com esta idéia, uma vez que para o período de 1970 a 2008, o número de turistas estrangeiros que chegaram ao país cresceu $1.920 \%$. Além disso, segundo a OMT (2011), enquanto o fluxo turístico em nível mundial cresceu em média apenas 4\% ao ano entre 1995 e 2008, o turismo estrangeiro no Brasil aumentou em média $11,8 \%$ ao ano para o mesmo período, o que demonstra que o país vem ganhando espaço no turismo mundial.

Nesse sentido, conhecer os determinantes da entrada de turistas estrangeiros no Brasil pode possibilitar aos gestores públicos e à iniciativa privada fazer um planejamento correto de investimentos e alocação de verbas visando que este setor conquiste um espaço ainda maior na economia brasileira. Entretanto, estimar de forma satisfatória os determinantes dos fluxos turísticos têm se revelado uma tarefa difícil porque não se consegue mensurar facilmente, por exemplo, as belezas naturais de cada região. Isso ocorre dada a subjetividade na avaliação dos destinos, pois não é possível quantificar quanto um é melhor que o outro e, além disso, cada pessoa pode fazer uma avaliação diferente. Para solucionar este problema e aqueles relacionados a encontrar variáveis para representar o tamanho e a qualidade da oferta dos serviços turísticos e a infraestrutura do destino, que também são fatores importantes levados em conta na tomada de decisão dos indivíduos 
de qual região ir, este artigo se propõe a avaliar os determinantes da entrada de turistas estrangeiros no Brasil no período de 2004 a 2008 através do modelo gravitacional do turismo com dados em painel e com dois efeitos fixos.

Os modelos gravitacionais têm sido frequentemente utilizados para explicar os fluxos turísticos entre os países, devido ao seu excelente poder de explicação. Partindo disso, sugere-se uma nova maneira de estimar a equação gravitacional, através de um modelo hierárquico em dois níveis, tendo como $1^{\circ}$ nível a equação gravitacional com dados em painel e dois efeitos fixos e, no $2^{\circ}$ nível, uma regressão em cross-section cuja variável dependente é o vetor de efeitos fixos gerado no modelo de $1^{\circ}$ nível que tem como variáveis explicativas as dummies que representam as atratividades de lazer de cada estado analisado, as dummies que captam a importância de um idioma em comum e a existência de uma fronteira, além da variável distância. Essa forma de estimação permitirá obter coeficientes não viesados, dado que o estimador de efeitos fixos corrige o viés de heterogeneidade, que é muito provável que esteja presente nas estimativas feitas pelos modelos gravitacionais com dados em cross-section ou em pooled data. Além disso, será possível estimar os parâmetros de características não observadas que são constantes ao longo do tempo, que nesse caso são a oferta de atratividades de lazer de cada estado, a distância, a fronteira e um idioma em comum.

A determinação desses fatores contribui para compreender melhor o fenômeno turístico podendo, assim, nortear políticas públicas com foco na maior atratividade turística e ser determinante para gerar melhores resultados para a Copa do Mundo de 2014 e as Olimpíadas de 2016, onde se espera que o fluxo de turistas estrangeiros ao país aumente consideravelmente.

O presente artigo está organizado em quatro seções, além desta introdução. A seção 2 apresenta algumas definições e conceitos do turismo bem como alguns dados do turismo no Brasil comparados aos mundiais. A seção 3 apresenta uma pequena revisão dos modelos gravitacionais aplicados ao turismo, a origem dos dados e a especificação do modelo propriamente dito. A seção 4 apresenta os resultados e, por fim, a seção 5 apresenta as conclusões.

\section{O TURISMO}

A Organização Mundial do Turismo (OMT) define o turismo como um conjunto de atividades, para fins de lazer, negócios ou outras atividades 
Determinantes da entrada de turistas estrangeiros nos estados brasileiros no período 2004 a 2008:

uma aborgagem com o modelo gravitacional do turismo

não-remuneradas no local visitado, realizadas pelas pessoas que estão em lugares distintos do seu habitual, por um período inferior a um ano.

As razões que motivam as pessoas a se deslocarem pelo mundo são várias. Segundo Santos (2004), são nove fatores que determinam os fluxos turísticos: i) o tamanho da população, que demonstra o potencial emissor do país de origem; ii) a cultura e sociedade, onde sociedades culturalmente próximas tendem a trocar mais fluxos turísticos; iii) os aspectos econômicos, que estão relacionados diretamente com renda - elasticidade-renda da demanda positiva - e o preço - elasticidade-preço da demanda negativa; iv) os motivos de viajar, que estão relacionados com a necessidade ou o desejo que pode ser satisfeito com uma viagem turística; $v$ ) a infraestrutura, como transporte, sistema de comunicação, energia elétrica, entre outros; vi) serviços e equipamentos turísticos e de apoio, que são os meios de hospedagem, serviços de informação turística, serviços de alimentação, locadoras de automóveis e imóveis, entre outros que tornam o destino turístico mais atrativo; vii) o deslocamento, que resulta no gasto de tempo, recurso financeiro e esforço físico; viii) os sistemas de distribuição do produto turístico, que facilitam sua compra; e ix) os aspectos legais relativos à entrada de turistas, que podem ser influenciados por políticas econômicas e sociais, como um câmbio diferenciado para turistas ou taxas para sua saída.

O estudo do setor turístico se deve principalmente devido a sua importância para a atividade econômica dos países, pois uma expansão deste setor permite aumentar o PIB, alavancar investimentos, gerar emprego e atrair divisas. Embora os estudos sobre o turismo tenham aumentado nos últimos anos a nível internacional devido, segundo Coelho et al $(2009$, p.3), a razões econômicas "porque essa forma de deslocamento desempenha um importante papel nos fluxos comercial e monetário entre as nações, sendo em alguns casos, a principal fonte de receitas de uma localidade ou até mesmo de um país", análises quantitativas aplicadas ao Brasil podem ser considerada ainda muito raras.

\subsection{Alguns Dados Estatísticos do Turismo}

Segundo a OMT (2011), o fluxo turístico em nível mundial aumentou em média 4\% ao ano entre 1995 e 2008. Analisando o mesmo período para o Brasil, os dados da Embratur (2010) demonstram que o fluxo de turistas 
estrangeiros que chegaram ao país cresceu em média 11,8\% ao ano. Esse fato evidencia que o turismo no Brasil cresce a uma taxa superior ao resto do mundo, trazendo à tona a necessidade de se conhecer os fatores que determinam esses fluxos. No ano 2005, o país recebeu o maior número de turistas estrangeiros de sua história, recebendo mais de 5,3 milhões de turistas naquele ano. Para o período de 1970 a 2008, o fluxo de turistas estrangeiros que chegaram ao país cresceu $1.920 \%$, conforme pode ser observado no gráfico 1 .

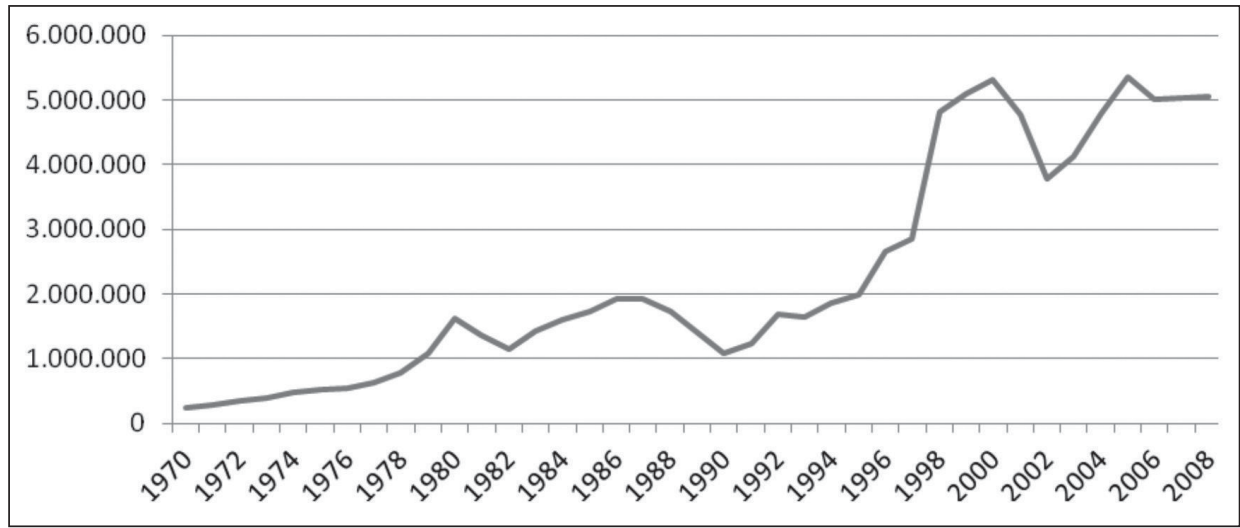

Gráfico 1: Chegada de Turistas Estrangeiros no Brasil no Período de 1970 a 2008.

Fonte: Elaboração própria com dados do MTUR (2010).

Apesar de algumas flutuações, há uma clara tendência de crescimento na entrada de turistas estrangeiros no Brasil principalmente a partir de 1996. Das flutuações mais recentes, observa-se uma brusca diminuição entre 2000 e 2002, provavelmente devido aos ataques terroristas ao World Trade Center. Além desta, o turismo também respondeu negativamente à crise imobiliária do segmento subprime nos Estados Unidos e ao surto de gripe aviária, ocorridos entre 2007 a 2009. Os cinco principais países emissores de turistas para o Brasil, segundo dados de 2008 são: Argentina, Estados Unidos, Itália, Alemanha e Chile. Somente a Argentina conta com uma participação de 20,15\%, enquanto que o Chile conta apenas com 4,75\%. Segundo dados do Ministério do Turismo (2010a), esses turistas que visitam o Brasil vêm principalmente em busca de lazer e preferem lugares com praias. Além disso, 45,5\% dos turistas estrangeiros viajam a lazer e 
Determinantes da entrada de turistas estrangeiros nos estados brasileiros no período 2004 a 2008:

uma aborgagem com o modelo gravitacional do turismo

$22,9 \%$ viajam a negócios, eventos ou convenções. Dos que viajam a lazer, $61,5 \%$ têm como motivo de viagem "sol e praia" enquanto $23,2 \%$ viajam por causa da "natureza, ecoturismo e aventura" (MTUR, 2009). A tabela 1 apresenta algumas informações dos dez estados que receberam o maior número de turistas estrangeiros para o ano de 2008.

Tabela 1: Estatísticas dos Estados Analisados para o ano de 2008

\begin{tabular}{l|r|c|c} 
Estados & $\begin{array}{c}\mathbf{N}^{\circ} \text { de turistas } \\
\text { estrangeiros }\end{array}$ & $\mathbf{N}^{\circ}$ de hotéis & $\begin{array}{c}\text { PIB em } \mathbf{R} \text { (a preços } \\
\text { constantes de 2004) }\end{array}$ \\
\hline São Paulo & 2.289 .640 & 4.392 & 849.783 .437 .649 \\
Rio de Janeiro & 766.083 & 1.639 & 290.753 .467 .242 \\
Rio Grande do Sul & 622.675 & 1.459 & 151.882 .598 .949 \\
Paraná & 605.217 & 1.353 & 169.021 .178 .154 \\
Bahia & 178.571 & 1.687 & 102.945 .003 .810 \\
Santa Catarina & 104.974 & 1.322 & 104.448 .833 .861 \\
Ceará & 98.590 & 612 & 50.917 .567 .436 \\
Pernambuco & 81.715 & 647 & 59.679 .601 .453 \\
Rio Grande do Norte & 70.541 & 448 & 28.081 .378 .603 \\
Mato Grosso do Sul & 49.508 & 497 & 21.588 .221 .698 \\
\hline
\end{tabular}

Fonte: Elaboração própria com dados da EMBRATUR, IBGE e RAIS. (2011)

Segundo a Embratur (2010), o estado de São Paulo é o destino mais procurado pelos turistas estrangeiros. Somente no ano de 2008, mais de 2,2 milhões ingressaram em São Paulo, o que representa aproximadamente 45\% do total de turistas recebidos pelo país. Além disso, esse estado possui o maior PIB do país e também o maior número de estabelecimentos ligados a rede hoteleira. Dos Estados analisados, o que apresentou o menor percentual de recebimento de turistas estrangeiros é o de Mato Grosso do Sul, com aproximadamente $1 \%$ do total recebido pelo Brasil. A Bahia apresentou o maior crescimento em termos de recebimento de turistas estrangeiros, saindo de um pouco mais de 130 mil turistas em 2004 para mais de 178 mil em 2008.

A importância do turismo para a economia brasileira é evidente se forem analisados alguns números do setor. $\mathrm{O}$ turismo se caracteriza como uma atividade prestadora de serviços e teve participação no setor de serviços em 
torno de 7,1\% em 2007 enquanto sua participação total sobre o PIB brasileiro foi de 3,6\%. Nesse mesmo ano, o turismo empregou 5,87 milhões de pessoas, representando $10,1 \%$ das ocupações do setor de serviços e, $6,2 \%$ do total de empregos formais da economia brasileira (IBGE, 2010a). Em 2007, 8,3\% da população empregada no mundo estavam trabalhando em atividades ligadas ao turismo, o que demonstra que o Brasil ainda está abaixo da média mundial e, sendo assim que possui um potencial de crescimento nesse setor para os próximos anos.

No Brasil, os rendimentos desse setor variam bastante de uma atividade para outra. Para melhor visualização, a tabela 2 apresenta a quantidade de pessoas ocupadas e seus respectivos salários, segundo as atividades características do turismo.

Não obstante, o turismo não tem impacto apenas na quantidade de emprego e renda do país, ele também pode ter um papel fundamental na entrada de dólares. Somente no período de 2004 a 2008, o aumento da receita cambial turística foi de 79,54\%, um valor bastante significativo que demonstra o aumento dos gastos dos estrangeiros no país (MTUR, 2010).

Tabela 2: Total de Pessoas Ocupadas e Rendimento Médio Anual do Total da Economia e das Atividades Características do Turismo - 2007

\begin{tabular}{l|r|r} 
Atividades & $\begin{array}{c}\text { Total de } \\
\text { Ocupações }\end{array}$ & $\begin{array}{c}\text { Rendimento } \\
\text { Médio Anual }\end{array}$ \\
\hline Serviços de alojamento & 346.900 & $\mathrm{R} \$ 10.415,11$ \\
Serviços de alimentação & 2.887 .001 & $\mathrm{R} \$ 3.726,01$ \\
Transporte ferroviário & 400 & $\mathrm{R} \$ 45.000,00$ \\
Transporte rodoviário & 1.176 .476 & $\mathrm{R} \$ 4.971,63$ \\
Transporte aquaviário & 29.165 & $\mathrm{R} \$ 40.082,29$ \\
Transporte aéreo & 44.472 & $\mathrm{R} \$ 62.173,95$ \\
Serviços auxiliares dos transportes & 187.295 & $\mathrm{R} \$ 19.546,70$ \\
Atividades deagências eorganizadores de viagens & 118.983 & $\mathrm{R} \$ 11.354,56$ \\
Aluguel de bens móveis & 41.886 & $\mathrm{R} \$ 16.258,42$ \\
Atividades recreativas, culturais e desportivas & 1.040 .034 & $\mathrm{R} \$ 5.826,73$ \\
\hline Total em Atividades Características do Turismo & 5.872 .612 & $\mathrm{R} \$ 6.111,21$ \\
Total da Economia & 94.713 .909 & $\mathrm{R} \$ 11.729,00$
\end{tabular}

Fonte: Elaboração própria com dados do IBGE - Economia do Turismo (2010)

Nota: * Em Valores Correntes 
Determinantes da entrada de turistas estrangeiros nos estados brasileiros no período 2004 a 2008: uma aborgagem com o modelo gravitacional do turismo

Aliado a isso, os investimentos federais realizados em 2003 neste setor foram de R \$ 1,09 bilhão, ao passo que em 2010, considerando apenas o acumulado entre os meses de Janeiro e Setembro, o investimento realizado somou R\$ 4,89 bilhões. Ou seja, houve aumento de mais de 3 bilhões de reais investidos em 7 anos. Para os próximos anos, devido à realização da Copa do Mundo de 2014 e as Olimpíadas no Rio de Janeiro em 2016, o investimento previsto é de $\mathrm{R} \$ 22,46$ bilhões em infraestrutura e organização, sem contar que "a competição deverá injetar, adicionalmente, $R \$ 112,79$ bilhões na economia brasileira, com a produção em cadeia de efeitos indiretos e induzidos" (ERNST \& YOUNG, 2010, p. 3). Porém, os investimentos não contemplam apenas a construção (ou reforma) de estádios e da estrutura necessária para transmitir os jogos, mas também a melhoria da rede hoteleira, reurbanização e embelezamento, segurança, rodovias, aeroportos, entre outros.

Com a Copa do Mundo de 2014, o cenário para geração de emprego e renda será bastante positivo. A expectativa é que o país receba $79 \%$ a mais de turistas, gerando cerca de 3,63 milhões de empregos por ano, de 2010 a 2014, e renda de R\$63,48 bilhões (ERNST \& YOUNG, 2010).

\footnotetext{
Trata-se dos maiores eventos esportivos do mundo, com forte apelo midiático e significativa capacidade de geração de emprego e renda para os setores envolvidos, direta e indiretamente, em sua realização, principalmente àqueles vinculados ao Turismo (ERNST \& YOUNG, 2010, p. 57).
}

Dessa forma, a Copa do Mundo trará benefícios para o desenvolvimento econômico do país, seja através das melhorias em infraestrutura ou através do crescimento econômico. Somente em infraestrutura serão investidos R \$ 14,54 bilhões, o que deve resultar em um aumento de R $\$ 7,18$ bilhões no PIB das cidades-sede da Copa do Mundo (Manaus, Fortaleza, Natal, Recife, Salvador, Brasília, Belo Horizonte, Cuiabá, São Paulo, Rio de Janeiro, Curitiba e Porto Alegre) (ERNST \& YOUNG, 2010). Ou seja, a tendência é de que o setor turístico do país tenha uma importância ainda maior para a economia nos próximos anos.

Assim, conclui-se que o turismo já tinha um impacto positivo na economia brasileira, dada a geração de empregos e renda que esse setor 
proporciona, e que, para os próximos anos, projeta-se uma grande expansão para este setor. Além disso, a Copa do Mundo beneficiará o país em termos de estrutura (como estradas, aeroportos, etc.) e aumento da demanda por empregos de até $70 \%$ em relação ao número de empregados que atualmente já trabalham nesse setor. Nesse sentido, é fundamental que o setor público e a iniciativa privada compreendam os determinantes da entrada de turistas estrangeiros no Brasil visando estabelecer estratégias para atrair esses visitantes. Para isso, este trabalho propõe a utilização do modelo gravitacional aplicado ao turismo visando encontrar os determinantes da entrada de turistas estrangeiros aos estados brasileiros.

\section{OS MODELOS GRAVITACIONAIS DO TURISMO}

Os modelos gravitacionais têm sido frequentemente utilizados para estimar os fluxos turísticos entre os países, devido ao seu excelente poder de explicação. Além disso, segundo Santos (2004), a equação gravitacional apresenta uma grande adequação ao turismo. Nesse sentido, far-se-á uso do modelo gravitacional buscando compreender os determinantes dos fluxos turísticos aos estados brasileiros. O presente artigo propõe uma nova maneira de estimar a equação gravitacional, através de um modelo hierárquico em dois níveis, tendo como $1^{\circ}$ nível a equação gravitacional com dados em painel e dois efeitos fixos e, no $2^{\circ}$ nível, uma regressão em cross-section cuja variável dependente é o vetor de efeitos fixos gerado no modelo de $1^{\circ}$ nível que tem como variáveis explicativas as dummies que representam as atratividades de lazer de cada estado analisado, as dummies que captam a importância de um idioma em comum e a existência de uma fronteira, além da variável distância. Essa forma permitirá obter coeficientes não viesados, dado que o estimador de efeitos fixos corrige o viés de heterogeneidade que é muito provável que esteja presente nas estimativas feitas com dados em cross-section ou em pooled data. Além disso, será possível estimar os parâmetros de características não observadas que são constantes ao longo do tempo, que nesse caso são a oferta de atratividades de lazer de cada estado, à distância, a fronteira e um idioma em comum. 
Determinantes da entrada de turistas estrangeiros nos estados brasileiros no período 2004 a 2008:

uma aborgagem com o modelo gravitacional do turismo

\subsection{Uma BREVE revisão}

No século XVII Isaac Newton formula a Lei da Gravidade, uma das mais importantes descobertas da física clássica. A partir dela, ele postula que a força de atração entre dois corpos é diretamente proporcional às suas massas e inversamente proporcional ao quadrado da distância entre os mesmos. A origem dos modelos gravitacionais está justamente na Lei de gravitação universal de Isaac Newton. De acordo com Matias (2004), o primeiro estudo que utilizou o modelo gravitacional para explicar as atividades humanas e suas interações com o espaço territorial deve-se a Carey, em 1865. Desde então, vários estudos foram desenvolvidos utilizando essa modelagem. Um dos artigos pioneiros na análise dos determinantes dos fluxos turísticos usando a equação gravitacional foi escrito por Waelbroeck e Canald (1964) apud Glejser e Dramais (1969), que utilizaram esse instrumental para os fluxos de turistas da Turquia. Já Glejser e Dramais (1969) estudaram os fluxos migratórios intra-regionais na Bélgica. Segundo Santos (2004), já por volta de 1940 os modelos gravitacionais passaram a dominar os esforços para explicar o comportamento espacial das populações humanas.

Segundo Khadaroo e Seetanah (2008), os modelos gravitacionais desfrutam de um sucesso no mundo acadêmico dada sua capacidade explicar vários tipos de fluxos inter-regionais e internacionais, incluindo a migração e o comércio internacional. Além disso, muitos trabalhos usaram a modelo gravitacional para prever fluxos turísticos. Entretanto, apesar desse sucesso todo, os estudos que utilizaram a equação gravitacional aplicados ao Brasil podem ser considerados escassos. Entre eles, destacam-se os trabalhos de Santos (2004) e Coelho et al (2009). Santos (2004) analisou os fluxos inter-regionais entre os estados brasileiros e Coelho et al (2009) os fluxos de turistas estrangeiros ao Brasil. No âmbito internacional, encontram-se uma maior quantidade de estudos aplicados ao turismo. Santos (2004) destacou os seguintes artigos: Taplin e Qiu (1997), que tinham o objetivo de verificar a capacidade de atração dos destinos turísticos da Austrália; Durbarry (2000), que realizou um estudo acerca do Reino Unido, visando determinar sua competitividade como destino turístico e Garcia (2002), que realizou um estudo acerca do turismo doméstico na Espanha. 
Além dos citados anteriormente, Gil-Pareja et al (2007) estudaram o impacto das embaixadas e dos consulados sobre o turismo e descobriram que tanto as embaixadas quanto os consulados alavancam em média o turismo em $30 \%$ em países desenvolvidos e $42 \%$ em países em desenvolvimento. Já Khadaroo e Seetanah (2008) estavam interessados em estimar o impacto que a infraestrutura de transportes tem sobre o turismo. Através de um painel dinâmico, esses autores concluíram que a infraesturura de transporte ajuda a explicar os fluxos turísticos. Archibald et al (2008) avaliaram a competitividade do turismo Caribenho também através de um painel dinâmico. Eles concluíram que os principais determinantes para a entrada de turistas no Caribe é a renda do país de destino, a relação entre os preços de mercado do país de origem e destino, a taxa de câmbio e as passagens aéreas.

Outro trabalho importante a ser ressaltado sobre o modelo gravitacional do turismo é de Dudokh (2009) que trata sobre quais os fatores que influenciam na decisão dos turistas da Jordânia a viajar para os países estrangeiros. Dudokh (2009) aborda variáveis como preços relativos, preços substitutos, renda per capita, preço do petróleo e como dummy, a guerra do Iraque em 2003. Os principais fatores estão relacionados com a visita de parentes, amigos ou viagens de negócios, o que torna os preços relativos insignificantes, principalmente em relação à viagem de negócios. Assim, o autor conclui que o único fator que realmente influencia na decisão de viajar são os preços dos bens substitutos, isto é, a comparação com o preço de tirar férias no exterior e na própria Jordânia.

O trabalho de Hanafiah et al (2010) buscou estimar a demanda turística da Malásia. Os autores identificaram que o comércio bilateral, a população, a renda, o preço e a distância geográfica entre a Malásia e os países asiáticos são os principais determinantes do turismo. A grande contribuição deles foi que existe uma correlação positiva entre os fluxos turísticos e os fluxos de comércio. Finalmente, a tabela 3 apresenta um resumo dos principais trabalhos analisados, suas variáveis e a forma de estimação utilizada.

Dessa forma, o modelo gravitacional se propõe a explicar a dinâmica da origem-destino dos fluxos turísticos a partir de seus determinantes, incorporando tanto a teoria quanto a prática, contribuindo, assim, para melhor compreender o fenômeno turístico (SANTOS, 2004). A partir da percepção 
Determinantes da entrada de turistas estrangeiros nos estados brasileiros no período 2004 a 2008: uma aborgagem com o modelo gravitacional do turismo

de que a modelagem gravitacional é um instrumental adequado para se conhecer os determinantes dos fluxos turísticos, passa-se a especificação do modelo utilizado neste artigo.

Tabela 3: Resumo dos principais trabalhos analisados.

\begin{tabular}{|c|c|c|c|}
\hline Autores & Ano & Metodologia / Dados & Variáveis utilizadas \\
\hline Matias & 2004 & $\begin{array}{l}\text { Cross-section linear } \\
\text { e MQO }\end{array}$ & Receita turística, distância e PIB de origem. \\
\hline Santos & 2004 & $\begin{array}{l}\text { Cross-section não } \\
\text { linear / linear e MQO }\end{array}$ & $\begin{array}{l}\text { Índice de atratividades proposto pelo Guia } \\
\text { Quadro rodas, extensão do litoral, No hotéis } \\
\text { e No de empregados do destino, Popula- } \\
\text { ção, PIB, Renda média, grau de educação } \\
\text { e urbanização da origem e a distância. }\end{array}$ \\
\hline $\begin{array}{l}\text { Bedo e } \\
\text { Dentinho }\end{array}$ & 2007 & $\begin{array}{l}\text { Cross-section linear } \\
\text { e MQO }\end{array}$ & $\begin{array}{l}\text { PIB de origem, } N^{\circ} \text { de camas do destino, } \\
\text { dummies para os países de origem e ilhas } \\
\text { de destino e uma dummy para cada ano } t \text {. }\end{array}$ \\
\hline Balali & 2007 & $\begin{array}{l}\text { Painel estático com } \\
\text { efeitos aleatórios }\end{array}$ & $\begin{array}{l}\text { PIB e população de origem e destino, taxa } \\
\text { de câmbio, distância e três dummies para } \\
\text { os países do Irã, Turquia e Paquistão. }\end{array}$ \\
\hline $\begin{array}{l}\text { Gil-Pareja } \\
\text { et al }\end{array}$ & 2007 & $\begin{array}{l}\text { Painel estático com } \\
\text { efeitos fixos para } \\
\text { origem e destino. }\end{array}$ & $\begin{array}{l}\text { PIB, PIB per capita, população da origem e } \\
\text { do destino, Nº de consulados e embaixadas } \\
\text { do destino, PPC, distância, dummies para } \\
\text { fronteira, idioma, litoral, ilha, APC. }\end{array}$ \\
\hline $\begin{array}{l}\text { Khadaroo e } \\
\text { Seetanah }\end{array}$ & 2008 & $\begin{array}{l}\text { Painel dinâmico atra- } \\
\text { vés do estimador de } \\
\text { Arellano e Bond }\end{array}$ & $\begin{array}{l}\text { PIB e População de origem, distância, pre- } \\
\text { ços relativos, dummies de idioma, fronteira } \\
\text { e de destinos alternativos, } N^{\circ} \text { de portos e } \\
\text { aeroportos, } \mathrm{N}^{\circ} \text { de hotéis e km de rodovias } \\
\text { pavimentadas do destino, }\end{array}$ \\
\hline $\begin{array}{l}\text { Archibald } \\
\text { et al }\end{array}$ & 2008 & $\begin{array}{l}\text { Painel dinâmico atra- } \\
\text { vés do estimador de } \\
\text { Arellano e Bond }\end{array}$ & $\begin{array}{l}\text { PIB e População da origem e do destino, } \\
\text { Preços domésticos do destino, Preços rela- } \\
\text { tivos, taxa de câmbio e distância. }\end{array}$ \\
\hline Coelho et al & 2009 & $\begin{array}{l}\text { Cross-section linear } \\
\text { e MQO }\end{array}$ & PIB e IDH de origem e a distância. \\
\hline Dudokh & 2009 & $\begin{array}{l}\text { Painel estático com } \\
\text { efeitos fixos e alea- } \\
\text { tórios }\end{array}$ & $\begin{array}{l}\text { PIB origem, preços relativos, preço do bem } \\
\text { substituto, custos de viagem e fatores qua- } \\
\text { litativos. }\end{array}$ \\
\hline $\begin{array}{l}\text { Hanafiah } \\
\text { et al }\end{array}$ & 2010 & $\begin{array}{l}\text { Painel estático com } \\
\text { efeitos aleatórios }\end{array}$ & $\begin{array}{l}\text { PIB, população da origem, Preços relativos, } \\
\text { comércio bilateral, distância }\end{array}$ \\
\hline
\end{tabular}

Fonte: Elaboração própria 
Magnus dos Reis • Jacqueline Lopes Nunes • Camila Flores Orth • Marcos Tadeu Caputi Lélis

\subsection{Especificação do modelo gravitacional do turismo}

Como já mencionado anteriormente, o modelo gravitacional do turismo tem origem na Lei de gravitação universal de Issac Newton. Essa lei é representada da seguinte forma:

$$
F=G\left(\frac{M_{1} M_{2}}{d^{2}}\right)
$$

em que: $F$ representa a força de atração entre as massas de dois corpos, $M_{1}$ e $M_{2}$ a massa do corpo 1 e 2 , respectivamente, $d$ representa a distância entre os dois corpos e $G$ a constante de gravitação universal.

A forma mais rudimentar do modelo gravitacional aplicado ao turismo faz uma analogia a Lei de gravitação universal de Newton e pode ser expressa da seguinte forma:

$$
f_{j i}=c\left(\frac{\text { fatrativa }_{j}^{\alpha} \text { frepulsiva }_{i}^{\beta}}{\text { fatrito }_{j}{ }^{\lambda}}\right)
$$

que ao extrair os logaritmos, visando linearizar a equação (2), obtém-se:

$$
f_{i j}=c+\alpha \text { fatrativa }_{j}+\beta \text { frepulsiva }_{i}-\lambda \text { fatrito }_{j}
$$

onde: $f_{j i}$, representa o fluxo de turistas estrangeiros de origem da região $i$ e de destino a região $j$, fatrativa representa as forças atrativas da região $j$, frepulsiva representa as forças repulsivas da região $i$, fatrito representa as forças de atrito entre as regiões $j$ e $i, c$ a constante e $\alpha, \beta$ e $\lambda$ os coeficientes das variáveis.

Cada uma dessas forças é influenciada por diversas variáveis. A seguir, as variáveis são apresentadas e explicadas, conforme a classificação de sua força. 
Determinantes da entrada de turistas estrangeiros nos estados brasileiros no período 2004 a 2008: uma aborgagem com o modelo gravitacional do turismo

\subsubsection{Forças de atrito}

Segundo Santos (2004), a força de atrito é a força que distancia ou aproxima duas determinadas regiões, ou seja, ela atua facilitando ou dificultando o fluxo de turistas. Para representar tal dificuldade, foi inserida no modelo uma variável referente à distância dos estados aos países, pois essa servirá como um fator de resistência ao turismo, uma vez que ela está extremamente correlacionada com os custos de transporte. ${ }^{5}$ Portanto, é esperado que o seu coeficiente estimado apresente um sinal negativo. Além disso, duas variáveis dummies foram inseridas para representar os fatores que aproximam as regiões. A primeira delas é quando o estado possui fronteira com um país selecionado na amostra (havendo fronteira a dummy assume valor $1 \mathrm{e}$, caso contrário 0). Essa dummy busca reduzir a resistência da entrada de turistas, pois os estados que possuem fronteira com os países selecionados da amostra deverão ter um maior número de turistas destes países dadas às facilidades de entrada pelas fronteiras. A outra dummy assume valor 1 quando o destino e a origem possuam o mesmo idioma oficial e, caso contrário 0. Dado que esse estudo analisa apenas o Brasil e esse tem como idioma oficial o português, foi inserida no modelo apenas uma variável para representá-lo. Sendo assim, essa dummy busca reduzir a resistência da entrada de turistas quando o país de origem tem o mesmo idioma que o de destino, pois ela facilita a comunicação entre as pessoas.

\subsubsection{Forças repulsivas}

As forças repulsivas são os fatores que determinam a saída temporária de algumas pessoas de seu país para países estrangeiros. Neste artigo, foram usadas três variáveis para representar as forças repulsivas de origem. O PIB per capita dos países servirá de proxy para a renda dos indivíduos. Assim, espera-se uma correlação positiva entre o fluxo de turistas estrangeiros ao Brasil e o PIB per capita do país de origem. Além disso, a população do país de origem foi inserida, uma vez que é razoável supor que quanto maior for a população de um país maior deverá ser a quantidade de indivíduos dispostos a viajar e, sendo assim, espera-se um coeficiente com sinal positivo.

Bedo e Dentinho (2007) encontram uma correlação positiva muito forte entre custo de transporte e a distância. 
Por fim, as variações na taxa de câmbio dos países estrangeiros podem influenciar os fluxos de turismo. Espera-se que depreciações da moeda estrangeira afetem negativamente a entrada de turistas estrangeiros ao Brasil, uma vez que suas moedas teriam seu poder de compra reduzido em relação ao dólar e, consequentemente ao real, mantendo constate a taxa de câmbio do real em relação ao dólar. Para os casos de uma apreciação da moeda estrangeira em relação ao dólar, o impacto deve ser positivo.

\subsubsection{Forças atrativas}

As forças atrativas são os fatores que determinam a escolha do destino pelos turistas. Sabendo que os turistas buscam principalmente lazer e negócios, faz-se necessário incluir no modelo gravitacional variáveis para representar tais atratividades. Para representar a atratividade de negócios, foi incluído no modelo o PIB dos estados, pois é de se esperar que quanto maior o nível de renda de uma determinada região, maiores serão as oportunidades de negócios. Os trabalhos que não incluíram em seus modelos esta variável podem ter sido mal especificados e, portanto sofrerem de viés de variável omitida. ${ }^{6}$

No que diz respeito às atratividades de lazer, os turistas levam em conta as belezas naturais, o tamanho e a qualidade da oferta de serviços turísticos e a infraestrutura proporcionada por cada estado. Santos (2004) incluiu duas variáveis em seu modelo para representar as atratividades das unidades da federação: número de atrativos turísticos, criado pelo Guia Quadro Rodas, e a extensão litorânea que cada estado possui. Entretanto, cabe salientar a dificuldade de mensurar os atrativos turísticos de cada estado uma vez que existe subjetividade na avaliação das belezas naturais dos destinos, dado que não é possível quantificar quanto um local é melhor que o outro e, além disso, cada pessoa pode fazer uma avaliação diferente. Não obstante, a extensão do litoral do destino também não implica necessariamente que haverá uma maior quantidade de belezas naturais, pois talvez o que realmente importe não seja o tamanho do litoral, mas sim a qualidade de suas praias. Sendo assim, ambas variáveis não são indicadas para obter uma correta especificação do modelo.

6 Dos estudos aplicados ao Brasil, Santos (2004) e Coelho et al (2009) não incluíram o PIB do destino em suas análises. 
Determinantes da entrada de turistas estrangeiros nos estados brasileiros no período 2004 a 2008: uma aborgagem com o modelo gravitacional do turismo

No que diz respeito à oferta dos serviços turísticos, é razoável pensar que por melhor que seja a as belezas naturais de uma determinada região, ela não receberá turistas se não possuir uma oferta de serviços turísticos de qualidade. Entende-se como oferta de serviços turísticos o número de leitos disponíveis em hotéis e pousadas levando em conta também sua qualidade. Nesse sentido, Bedo e Dentinho (2007) incluíram em seu modelo o número de leitos oferecidos pelo destino. Porém, usar apenas o número de camas como uma proxy para representar a oferta de serviços do destino também não é aconselhável, pois dessa forma não se leva em conta a qualidade dos hotéis e dos quartos disponíveis. Por outro lado, a inclusão do número de hotéis e de empregados, como foi feita por Santos (2004), também não representa de forma satisfatória esta oferta, pois, por exemplo, pode haver apenas um grande hotel que ofereça uma maior quantidade de quartos do que dez hotéis de menor tamanho. Não obstante, uma maior oferta de serviços turísticos não garante necessariamente a ocupação total da mesma. Mais uma vez, tais variáveis não são as mais recomendadas.

A infraesturura disponível pelo estado também influencia na decisão dos turistas. Aspectos como o nível de segurança, qualidade de estradas, aeroportos, restaurantes e cumprimento de leis são alguns exemplos de aspectos levados em conta pelos turistas na sua tomada de decisão de qual destino visitar. Mais uma vez, todas essas características são difíceis de serem mensuradas. Sendo assim, as belezas naturais, a oferta de serviços turísticos e a infraestrutura sofrem problemas de mensuração, muitas vezes por falta de dados e outras por dificuldade de se encontrar variáveis para representar tais fatores.

Como as variáveis que têm sido frequentemente utilizadas nos modelos gravitacionais para representar a oferta de atratividades turísticas de lazer podem não representar de forma satisfatória as atratividades dos destinos e, por isso elas devem repensadas, este artigo propõem estimar o modelo gravitacional do turismo com dados em painel e dois efeitos fixos, um para captar características não observadas que são constantes ao logo do tempo e outra para capturar choques específicos no tempo $t$. O efeito fixo captará as características que são constantes ao longo do tempo e que influenciam os fluxos de turistas aos estados brasileiros, isto é, as atratividades turísticas de lazer dos destinos. Além disso, o estimador de efeitos fixos irá resolver 
os problemas de heterogeneidade bilateral do destino $j$ e origem $i$ que está presente na maioria das análises em cross-section. Ele permite ainda a endogeneidade dos regressores com as características não observadas que são constantes ao longo do tempo.

\subsection{A abordagem econométrica}

os dados originais foram transformados para forma log-linear, pois, através disso, os coeficientes estimados pelo modelo estarão expressos diretamente em termos de elasticidade, o que facilita a interpretação dos parâmetros estimados. Entretanto, dado o elevado número de estados, países e anos envolvidos na amostra, em alguns momentos a variável dependente (fluxo de turistas) apresentou valores iguais a 0. Quando isso ocorre, não é possível transformar os valores iguais a zero para logaritmo se o modelo proposto for estimado de forma linear. Neste caso, para o ano de 2004, 2005, 2006, 2007 e 2008 há, respectivamente, 5, 1, 4, 4 e 2 observações nas quais o fluxo de turistas estrangeiros é 0 , ou seja, apenas $2,5 \%, 0,5 \%, 2 \%$, $2 \%$ e $1 \%$ do total da amostra para cada ano. Para todo o período, a variável dependente tem o valor igual a 0 em 16 observações, isso representa apenas $1,6 \%$ do total da amostra para todo o período analisado.

Para solucionar o problema da transformação dos dados para a forma log-linear, a literatura dos modelos gravitacionais sugere três possibilidades. A primeira delas é proposta por Wang e Winters (1992) e Frankel et al (1993) que sugerem excluir da amostra as observações que apresentarem valores iguais a 0 . Assim, tornar-se-ia possível transformar os dados restantes para forma log-linear e após estimar o modelo. Porém, essa possibilidade não é indicada, pois ela, ao excluir observações da amostra, retira informações importantes sobre as razões pelas quais ocorreu um tão baixo fluxo. Além disso, conforme Greene (2008), essa alternativa aumenta a probabilidade de se obter parâmetros viesados, uma vez que quanto menor a amostra maior será o viés.

Outra opção frequentemente utilizada é estimar o modelo pelo método de tobit. ${ }^{7}$ No entanto, segundo Azevedo (2004), os resultados da utilização

A estimação através do método tobit trata diretamente os dados da amostra censurada para a variável endógena. Este procedimento incorpora implicitamente as informações das observações iguais à zero, com as observações positivas sendo utilizadas para estimar o fluxo de turistas, dado que ele é positivo, enquanto as observações iguais a zero são usadas para estimar a probabilidade de o fluxo de turistas ser positivo. 
Determinantes da entrada de turistas estrangeiros nos estados brasileiros no período 2004 a 2008: uma aborgagem com o modelo gravitacional do turismo

do método de tobit têm sido bastante parecidos com os do método de MQO nos quais o percentual da variável dependente com valores iguais a zero é baixo (como no caso do presente artigo). Além disso, Maddala (2003, p. 178) afirma que é necessário entender o que o modelo de tobit realmente diz. Nesse sentido, o método de tobit permite que o valor da variável dependente seja negativo, entretanto, isso não é observado por causa da censura. Assim, os valores zero representam impossibilidades de observação. Esse não é o caso dos valores dos fluxos de turistas usados nas equações gravitacionais, pois esses fluxos não podem assumir valores negativos. Sendo assim, os valores zeros observados não são devidos a censura, mas à decisão dos indivíduos e, portanto, o método de tobit não é indicado neste caso.

A última alternativa, conforme salienta Kume e Piani (2000), é substituir na amostra os valores que apresentarem valor igual a 0 por valores muito pequenos, tais como 0,001 e só após fazer a transformação logarítmica. Dessa forma, também se torna possível estimar o modelo pelo método do MQO. Entretanto, Frankel et al (1995) salientam que o logaritmo de um número muito pequeno torna-se um número negativo muito grande e, como o método do MQO dá uma ponderação maior para valores extremos, os valores que foram substituídos por um valor pequeno $(0,001)$ recebem uma importância muito grande nas estimativas. Nesse sentido, é interessante não usar um número tão pequeno quanto o sugerido por Kume e Piani. Sendo assim, a opção escolhida foi por substituir as informações da variável dependente (fluxos de turistas estrangeiros) iguais a 0 por valores iguais a $1 .{ }^{8}$

Além disso, o modelo gravitacional com dados em cross-section sofre problemas de especificação, uma vez que ele não é capaz de lidar com a heterogeneidade bilateral do destino e da origem que está presente nos fluxos turísticos. Assim, a equação gravitacional utilizando dados em painel com efeitos fixos corrige esse problema e, sendo assim é indicada. Este tipo de abordagem foi recomendada inicialmente por Matyas (1997) e Anderson e van Wincoop (2003) e vêm sendo utilizada nos modelos gravitacionais aplicados aos fluxos de comércio.

A inclusão de efeitos fixos para as características não observadas que são constantes no tempo para cada par estado $j$ e país $i$ (aqui repre-

Bedo e Dentinho (2007) usaram o modelo gravitacional aplicado ao turismo e substituíram os valores iguais a zero encontrados em sua variável dependente por I. 
sentada por $\mu_{i}$ ) irá captar as características que muitas vezes são difíceis de quantificar ou ainda que não existam dados disponíveis, tais como as belezas naturais dos destinos, a quantidade e qualidade de oferta de serviços turísticos e a infraestrutura disponível nos estados. ${ }^{9}$ Já a inclusão de um efeito fixo para cada ano $t$ capturará os choques específicos do tempo $t$ que influenciam os fluxos de turistas. Esse efeito fixo captura choques não percebidos pelas variáveis incluídas no modelo, tais como o surto de gripe aviária $\mathrm{A}(\mathrm{H} 5 \mathrm{~N} 1)$ ocorrido em 2005 , o surto de gripe $\mathrm{A}(\mathrm{H} 1 \mathrm{~N} 1)$ de 2009, a crise econômica mundial decorrente da crise imobiliária do segmento subprime nos Estados Unidos de 2007. Fatores climáticos, como o tsunami no oceano índico de no final de 2004, também podem determinar mudanças nos fluxos turísticos. Sendo assim, tais acontecimentos podem não somente afetar a renda dos agentes econômicos, mas também suas expectativas. Todos os choques citados acima podem ter afetado negativamente as expectativas dos agentes ou sua renda e, portanto, devem ter um impacto negativo sobre os fluxos de turistas.

Porém, ao incluir o efeito fixo para as características que constantes ao longo do tempo para cada par de destino $j$ e origem $i$, não é possível estimar as variáveis conhecidas que são constantes ao longo do tempo, tais como a distância entre a região $j$ e $i$. O presente artigo sugere então, estimar um modelo hierárquico em dois níveis para se obter os coeficientes de variáveis que são constantes ao longo do tempo. Um modelo hierárquico institui uma ordem na estimação dos coeficientes a serem estimados. Neste caso, relacionam-se as variáveis que não são constantes ao longo do tempo - tais como o PIB per capita, a população, a taxa de câmbio dos países de origem e o PIB dos estados - em um $1^{\circ}$ nível e variáveis que são constantes ao longo do tempo - tais como a distância, a fronteira, o idioma e as dummies de atratividades de lazer do destino - em um $2^{\circ}$ nível. No modelo de $1^{\circ}$ nível tem-se uma estrutura de dados em painel com dois efeitos fixos e no de $2^{\circ}$ nível um modelo com dados em cross-section.

\footnotetext{
Segundo Wooldridge (201 I, p.430), alguns fatores não observados podem não ser exatamente constantes, mas podem ser considerados aproximadamente constates em períodos de até cincos anos. Sendo assim, como o período de tempo analisado neste artigo é de 5 anos, pode-se considerar a oferta de serviços turísticos - o número e a qualidade dos hotéis disponíveis - e a infraestrutura disponíveis - tais como número e qualidade dos restaurantes, nível de segurança, qualidade das estradas e etc. - como sendo constantes em períodos curto de tempo, uma vez que mudanças dessas características exigem um certo período de tempo para serem concluídas.
} 
Determinantes da entrada de turistas estrangeiros nos estados brasileiros no período 2004 a 2008: uma aborgagem com o modelo gravitacional do turismo

Nesse sentido, a equação a ser estimada em $1^{\circ}$ nível assume a seguinte forma:

$$
f_{i j t}=\beta_{0}+\sum_{k=1}^{k} \beta_{k} \cdot X_{i j t}+\sum_{t=1}^{5} \beta_{t} \cdot D A_{t}+\mu_{i}+v_{i j t}
$$

onde:

$f_{i j t}$ é vetor com o número de turistas estrangeiros do país $i$ com destino ao estado $j$ no ano $t$;

$\beta_{0}$ representa a constante;

$X_{i j t}$ é o conjunto de $k$ variáveis que representam as forças atrativas de destino $j$ e repulsivas da origem $i$ no ano $t$;

$\beta_{k}$ é o vetor de parâmetros das variáveis $X_{i j t}$;

$D A_{t}$ é um conjunto de variáveis dummies de tempo;

$\beta_{t}$ é o vetor de parâmetros das dummies anuais;

$\mu_{i}$ é o efeito fixo das características não observadas que são constantes ao longo do tempo do destino $j$ e origem $i$;

$v_{i, t}$ é o vetor de resíduos randômicos.

A partir do vetor de parâmetros $\mu_{i}$ calculados no modelo de $1^{\circ}$ nível, constrói-se o modelo de $2^{\circ}$ nível, nesse caso um cross-section das variáveis que são constates ao longo do tempo.

$$
\mu_{i}=\sum_{m=1}^{m} \eta_{m} \cdot \psi_{j}+\varepsilon_{j}
$$

onde:

$\mu_{i}$ é o efeito fixo das características não observadas que são constantes ao longo do tempo do destino $j$ e origem $i$ estimado pelo modelo de $1^{\circ}$ nível; $\Psi_{i j}$ é o conjunto de $m$ variáveis que representam as forças atrativas de destino $i$ e as forças de atrito entre $i$ e $j$;

$\eta_{m}$ é o vetor de parâmetros das variáveis $\Psi_{i j}$;

$\varepsilon_{i t}$ é o vetor do erro aleatório. 
As variáveis que representam as forças atrativas do destino $j$ são representadas por dez variáveis dummies, uma para cada estado analisado como segue, São Paulo, Rio de Janeiro, Paraná, Rio Grande do Sul, Bahia, Santa Catarina, Pernambuco, Ceará, Mato Grosso do Sul e Rio Grande do Norte. Quando o par de efeitos fixos entre a origem $i$ e destino $j$ se refere a sua dummy de destino $j$, ela assume valor 1 e 0 , caso contrário. Desta forma, será possível quantificar os aspectos das atratividades da oferta de lazer de cada estado que são constantes ao longo do tempo. Isso permite avaliar quais são os estados que apresentam maior oferta de atratividades de lazer. Não esquecendo que, entre todas essas atratividades, encontram-se não somente suas belezas naturais, mas também aspectos como a quantidade e qualidade de serviços turísticos e infraestrutura da região, que são consideradas constantes no curto prazo. Ambas as regressões foram estimadas usando o modo robusto do Stata, ou seja, com um erro padrão robusto que leva em conta a possível presença de heteroscedasticidade e autocorrelação dos resíduos.

\subsection{Origem dos dados}

A variável dependente - número de turistas estrangeiros que chegaram ao país por unidades da federação - foi obtida a partir do anuário estatístico da EMBRATUR. Foram selecionados os dez estados brasileiros que receberam o maior número de turistas estrangeiros e os vinte principais países de origem, para o período de 2004 a 2008. ${ }^{10}$ O PIB de cada estado foi obtido no IBGE e colocado a preços de 2004 pelo IPCA, também obtido na mesma fonte. A variável distância foi construída pela distância em linha reta em quilômetros entre os principais aeroportos de destino das capitais estaduais aos principais aeroportos de origem das capitais nacionais. Essas medidas foram calculadas através do Google Earth. A amostra possui 200 observações para cada ano o que gera um total de 1.000 observações para todo o período analisado. A taxa de câmbio, o PIB per capita dos países de origem (em dólares a preços constantes de 1990) e o deflator do PIB,

\footnotetext{
Os dez estados brasileiros de maior destino turístico representavam para o período analisado, em média, aproximadamente $97 \%$ do destino dos turistas estrangeiros que ingressam no país. Já o conjunto dos vinte principais países constituía em média aproximadamente $88 \%$ das chegadas de turistas estrangeiros para o período analisado. Os estados e os países incluídos na amostra se encontram na tabela A. I em anexo.
} 
Determinantes da entrada de turistas estrangeiros nos estados brasileiros no período 2004 a 2008:

uma aborgagem com o modelo gravitacional do turismo

utilizado para calcular a taxa de câmbio real dos países, foram obtidos das Nações Unidas. A população foi obtida do Banco Mundial.

\section{RESULTADOS}

Os resultados do modelo em $1^{\circ}$ nível com dados em painel estão apresentados na tabela 4. A maioria das variáveis do modelo apresentou coeficientes estimados de acordo com o sinal esperado. A única exceção foi o coeficiente negativo do PIB per capita dos países de origem, porém ele não foi significante neste artigo. Sendo assim, conclui-se que o PIB per capita do país de origem não têm influência sobre os fluxos turísticos para os estados brasileiros. Cabe ressaltar que esse curioso resultado também foi encontrado por Archibald et al (2008) e Gil-pareja et al (2009). No caso de Gil-pareja et al (2009), seu coeficiente foi significativo. Esses autores atribuíram esse resultado inesperado à correlação existente entre o PIB per capita e a população, o que revela a provável existência de problemas de multicolinearidade.

Tabela 4. Resultados do Modelo em $1^{\circ}$ nível estimado em dados em painel com two-way-effects

\begin{tabular}{l|c|c|c} 
Variáveis & Coeficiente & ó & p-valor \\
\hline PIB do Estado & 2,38525 & 0,81047 & 0,003 \\
PIB per capita do País & $-0,63632$ & 0,84951 & 0,454 \\
População do País & 8,80595 & 3,18212 & 0,006 \\
Câmbio real do País & $-0,98621$ & 0,43065 & 0,022 \\
2005 & 0,02830 & 0,06879 & 0,681 \\
2006 & $-0,30595$ & 0,12841 & 0,017 \\
2007 & $-0,44015$ & 0,18874 & 0,020 \\
2008 & -0.64823 & 0,24315 & 0,008 \\
Constante & -196.8714 & 58.60804 & 0,001 \\
\hline $\mathrm{N}^{0}$ de observações & & & 1.000 \\
Teste de Hausman: $\mathrm{X}^{2}(5)$ & & & $43,86[0,00]$ \\
$\mathrm{F}(8,792)$ & & & $4,35[0,00]$
\end{tabular}

Fonte: Elaboração própria

Nota: Todas as variáveis estão em logaritmo, exceto as dummies. 
Assim como no estudo de Archibald et al (2008) e Gil-pareja et al (2009), o PIB de destino apresentou um parâmetro significativo e com o sinal esperado. No caso dos estados brasileiros, um aumento de $10 \%$ no PIB estadual provoca um aumento em $23,85 \%$ na entrada de turistas estrangeiros, o que demonstra a importância do PIB do destino como uma proxy para a atratividade de negócios e como um fator determinante dos fluxos turísticos. A população e o câmbio da origem também apresentaram um coeficiente de acordo com o sinal esperado. Um crescimento populacional de $1 \%$ gera um aumento de 8,8\% nos fluxos de turistas estrangeiros ao Brasil. Além disso, uma depreciação de $10 \%$ da moeda local frente ao dólar dos países de origem provoca uma queda de $9,8 \%$ na entrada de turistas, o que evidencia a perda de poder de compra de sua moeda frente ao dólar.

Os efeitos fixos específicos em cada ano $t$ demonstraram que apenas no ano de 2005 nenhum choque externo ocorreu, uma vez que seu coeficiente não foi significativo. Já nos anos de 2006, 2007 e 2008, as dummies apresentaram um coeficiente com sinal negativo e significativo. Dado que esse efeito fixo captura os choques não percebidos pelas variáveis incluídas no modelo específicos do ano $t$, buscou-se encontrar possíveis explicações para esses resultados. O surto de gripe aviária A(H5N1) ocorrido em 2005 na Ásia cujo impacto pode ter ocorrido nos meses seguintes na América Latina e a crise econômica mundial no início de 2008, podem ter causado uma queda nos fluxos turísticos nos anos de 2006, 2007 e 2008 de aproximadamente de $26 \%, 36 \%$ e $48 \%$, respectivamente, em comparação aos fluxos esperado pelo modelo para esses anos. ${ }^{11}$

Os resultados do modelo em $2^{\circ}$ nível, neste caso um modelo em crosssection das variáveis que são constates ao longo do tempo como regressores e como variável dependente o efeito fixo gerado no modelo em $1^{\circ}$ nível, encontram-se na tabela 5. A distância entre a origem e o destino para determinar os fluxos turísticos demonstrou ser um fator relevante, assim como nos estudos de Santos (2004) e Coelho (2009). A distância apresentou um coeficiente negativo e significativo, conforme esperado. Além disso, não se percebeu a presença do efeito fronteira sobre os fluxos de turistas, pois sua

Dado que o modelo foi estimado em log, o coeficiente estimado para qualquer variável dummy é: [exp (coeficiente da dummy)]. Já seu percentual equivalente pode ser calculado da seguinte forma: [((exp (coeficiente da dummy))-I) $\times$ (00]. 
Determinantes da entrada de turistas estrangeiros nos estados brasileiros no período 2004 a 2008:

uma aborgagem com o modelo gravitacional do turismo

dummy não foi significativa. Uma possível explicação encontrada é que, ao se analisar os dados estatísticos dos fluxos de turistas estrangeiros que chegaram ao país, percebe-se que os estados de São Paulo e Rio de Janeiro representam aproximadamente $60 \%$ dos fluxos de turistas estrangeiros que chegaram ao Brasil em 2008, sendo que ambos não possuem fronteira com nenhum país. A dummy referente ao idioma português apresentou um coeficiente com o sinal positivo, conforme esperado.

Tabela 5. Resultados do Modelo em $2^{\circ}$ nível estimado em cross-section

\begin{tabular}{|c|c|c|c|}
\hline Variáveis & Coeficiente & ó & p-valor \\
\hline Distância & $-10,1455$ & 0.8286 & 0,000 \\
\hline Português & 11,9782 & 0.7123 & 0,000 \\
\hline Fronteira & $-4,3324$ & 3.8810 & 0,266 \\
\hline São Paulo & 85,5917 & 7.2807 & 0,000 \\
\hline Rio de Janeiro & 87,1247 & 7.3290 & 0,000 \\
\hline Paraná & 87,7429 & 7.2474 & 0,000 \\
\hline Rio Grande do Sul & 86,3056 & 7.4275 & 0,000 \\
\hline Bahia & 86,9539 & 7.4434 & 0,000 \\
\hline Ceará & 87,6855 & 7.4271 & 0,000 \\
\hline Santa Catarina & 84,6022 & 7.1553 & 0,000 \\
\hline Pernambuco & 87,2154 & 7.4897 & 0,000 \\
\hline Mato Grosso do Sul & 87,6693 & 7.4725 & 0,000 \\
\hline Rio Grande do Norte & 88,8607 & 7,4475 & 0,000 \\
\hline \multicolumn{3}{|l|}{$\mathrm{N}^{\circ}$ de observações } & 200 \\
\hline \multicolumn{3}{|l|}{$F(13,187)$} & $66,10[0,00]$ \\
\hline \multicolumn{3}{|l|}{$\mathrm{R}^{2}$} & 0,45 \\
\hline
\end{tabular}

Fonte: Elaboração própria

Nota: Todas as variáveis, exceto as dummies estão em logaritmo.

A inclusão de uma variável dummy para cada destino analisado, visando representar as características não observadas que são constantes ao longo do tempo, mas que influenciam os fluxos de turistas, permitiu mensurar as atratividades turísticas de lazer de cada estado. Entre todas essas atratividades, encontram-se não somente as belezas naturais dos destinos, mas também aspectos como a quantidade e qualidade de serviços turísticos e a infraestrutura da região, que podem ser consideradas constantes no curto 
prazo. Para facilitar a visualização, foi construído um ranking dos estados com os maiores níveis de atratividades que estão dispostos na tabela 6 .

Tabela 6. Ranking de atratividades dos estados

\begin{tabular}{c|l|c} 
Ranking & Estados & Índice de Atratividades \\
\hline $1^{\circ}$ & Rio Grande do Norte & 88,8607 \\
$2^{\circ}$ & Paraná & 87,7429 \\
$3^{\circ}$ & Ceará & 87,6855 \\
$4^{\circ}$ & Mato Grosso do Sul & 87,6693 \\
$5^{\circ}$ & Pernambuco & 87,2154 \\
$6^{\circ}$ & Rio de Janeiro & 87,1247 \\
$7^{\circ}$ & Bahia & 86,9539 \\
$8^{\circ}$ & Rio Grande do Sul & 86,3056 \\
$9^{\circ}$ & São Paulo & 85,5917 \\
$10^{\circ}$ & Santa Catarina & 84,6022
\end{tabular}

Fonte: Elaboração própria

Um dos resultados mais surpreendentes desta análise foi que São Paulo apresentou um dos menores índices de atratividades, ocupando apenas a nona posição entre os dez estados analisados. Entretanto, São Paulo é o estado que mais recebe turistas estrangeiros do país. Como isto seria possível? A explicação se deve ao fato de que São Paulo possuiu o maior PIB do país, ou seja, apresenta a maior atratividade de negócios. Sendo assim, esse resultado sugere que os turistas estrangeiros que vão a São Paulo estão em busca de negócios e não de lazer. Além disso, o estado com maior atratividade de lazer foi o estado do Rio Grande do Norte que é o justamente o estado que apresenta o segundo menor PIB dos estados analisados. Portanto, é muito provável que os turistas estrangeiros vão à Rio Grande do Norte estão em busca de lazer e não de negócios.

\section{CONCLUSÃO}

O turismo é uma atividade que vem ganhando cada vez mais importância na economia brasileira. A entrada de turistas estrangeiros no país cresceu $1.920 \%$ no período de 1970 a 2008. No ano de 2007 , o número de empregados ligados a atividades turísticas correspondia a $6,2 \%$ do total de empregos 
Determinantes da entrada de turistas estrangeiros nos estados brasileiros no período 2004 a 2008: uma aborgagem com o modelo gravitacional do turismo

na economia brasileira. Esse número é cerca de dois pontos percentuais menor do que o setor emprega em nível mundial, ou seja, ainda há espaço para esse segmento ganhar participação no PIB nacional, ainda mais se for levada em conta a Copa do Mundo de 2014 e as Olimpíadas de 2016 no Rio de Janeiro que irão ocorrer no país. Nesse sentido, torna-se fundamental que o setor público e privado compreendam alguns dos determinantes da entrada de turistas estrangeiros ao Brasil visando estabelecer estratégias para atrair visitantes. Visando ajudar a compreensão deste fenômeno, este artigo propôs uma nova maneira de utilizar o modelo gravitacional para estimar os fluxos turísticos, através de um modelo hierárquico em dois níveis, tendo como $1^{\mathrm{o}}$ nível a equação gravitacional com dados em painel e dois efeitos fixos e, no $2^{\circ}$ nível, uma regressão em cross-section cuja variável dependente é o vetor de efeitos fixos gerado no modelo de $1^{\circ}$ nível.

Os resultados encontrados indicam que para um aumento de $10 \%$ no PIB do estado, o fluxo de turistas estrangeiros aumenta em 23,85\%. Já um crescimento populacional do país de origem de $1 \%$ provoca um aumento de $8,8 \%$ nos fluxos de turistas estrangeiros ao Brasil. Além disso, uma depreciação de $10 \%$ da moeda local frente ao dólar dos países de origem provoca uma queda de $9,8 \%$ na entrada de turistas. A distância entre a origem e o destino demonstrou ser um fator de resistência ao turismo. Já o idioma em comum contribui para aumentar os fluxos de turistas. Não obstante, não se percebeu a presença do efeito fronteira sobre os fluxos de turistas, pois sua dummy não foi significativa.

O resultado mais surpreendente desta análise foi que São Paulo apresentou um dos menores índices de atratividades, ocupando apenas a nona posição entre os dez estados analisados. Entretanto, São Paulo é o estado que mais recebe turistas estrangeiros do país. Como isto seria possível? A explicação se deve ao fato de que São Paulo possuiu o maior PIB do país, ou seja, apresenta a maior atratividade de negócios. Sendo assim, os resultados sugerem que os turistas estrangeiros que vão a São Paulo estão em busca de negócios e não de lazer. Por fim, para futuras pesquisas, seria interessante utilizar um painel dinâmico ou outro estimador para painel estático. Um estimador não linear conhecido como Pseudo Máxima Verossimilhança de Poisson (PMVP) é indicado, pois produz estimativas dos parâmetros consistentes mesmo com erros heterocedásticos e permite incluir na análise, 
sem fazer qualquer transformação, os fluxos turísticos com valores iguais a zero. Essa PMVP é um estimador frequentemente utilizado para dados de contagem, como no caso deste estudo.

\title{
DETERMINANTS OF TOURISTS ENTRY IN THE BRAZILIAN STATES FROM 2004-2008: GRAVITATIONAL MODEL AP- PROACH APPLIED TO TOURISM
}

\begin{abstract}
Tourism is an important economic activity for countries, for an expansion of this sector allows increasing GDP, boost investment, creating jobs and attracting foreign exchange. In recent years, this sector has gained importance in the Brazilian economy, since there is a significant increase in foreign tourists in the country. For the next few years due to Brazil hosting the World Cup 2014 and the Olympics in Rio de Janeiro in 2016, the inflow of foreign tourists in the country will increase considerably. In this sense, it is essential that the public and private sector understand the determinants of tourist flows to the country, in order to establish strategies to attract visitors. For this, we proposed an alternative way of estimating the gravity model through a hierarchical model on two levels, with the 1 st level being the gravity equation with panel data and two fixed effects and, on the 2 nd level, a regression in cross-section. The most surprising result of this analysis was that the state of São Paulo had one of the lowest rates of leisure attractiveness of the analyzed states. However, São Paulo is the state that received the most foreign tourists in the country. The apparent contradiction is explained by the fact that São Paulo has the largest GDP in the country, ie, presents a more attractive business. Therefore, this result suggests that foreign tourists who come to São Paulo are seeking business and not leisure.
\end{abstract}

Keywords: tourist flows; Gravitational Model; Panel Data.

JEL Classification: L83; C23; C21. 
Determinantes da entrada de turistas estrangeiros nos estados brasileiros no período 2004 a 2008: uma aborgagem com o modelo gravitacional do turismo

\section{REFERÊNCIAS BIBLIOGRÁFICAS}

ANDERSON, J. E., VAN WINCOOP, E. "Gravity with Gravitas: A Solution to the Border Puzzle". American Economic Review 93, 170- 192. 2003.

ARCHIBALD, X., LACORBINIÈRE, J., MOORE, W. Analysis of Tourism Competitiveness in the Caribbean: A Gravity Model Approach. 29th Annual Review Seminar of Central Bank of Barbados, July 2008.

AZEVEDO, A. F. Z. O Efeito do Mercosul sobre o comércio: Uma análise com o modelo gravitacional. Brasília: IPEA, 2004. (Volume 34, número 2).

BALALI, A. Determinants of Regional-International Tourist Attraction among the Member Countries of ECO. Thesis submitted for the degree of Master of Science (M.Sc.) in Management of Tourism and Hospitality. Lulea University of Technology. 2007.

BANCO MUNDIAL. World Development Indicators. Portal Oficial. Disponível em: $<$ http://data.worldbank.org/data-catalog/world-development-indicators $>$. Acesso em: 21. Set. 2010.

BEDO, D., DENTINHO, T. P. Avaliação dos destinos turísticos das ilhas dos açores com base em modelos gravitacionais. In: Revista Portuguesa de Estudos Regionais, 1. Quadrimestre, p. 35-52. 2007.

COELHO, C. C., FERRREIRA, W. R., CAVAlCANTI; J. E. A.. Análise Estatística Multivariada e Aplicação do Modelo Gravitacional aos Fluxos Turísticos para o Brasil. Revistas Una, Belo Horizonte, n.3, p. 35-54, Set - Dez 2009.

DUDOKH, D. What Factors Affect the Destinations Choice of Jordanian Tourists? A Panel Data Analysis. Tese de Doutorado. Högskolan Dalarna University. Department of Economics and Social Science. 2009.

EGGER, P. "Alternative Techniques for Estimation of Cross-Section Gravity Models". Review of International Economics, 13(5), 881-891, 2005 
EMBRATUR. Anuário Estatístico. Disponível em: <www.braziltour.com/ site/br/dados_fatos/conteudo/lista.php?in_secao=308>. Acesso em: 11 Set. 2010 .

ERNST \& YOUNG; FGV Projetos (Fundação Getúlio Vargas). Brasil Sustentável: Impactos Sócioeconômicos da Copa Mundo 2014. Disponível em: $<$ http://www.fgv.br/fgvprojetos/>. Acesso em: 06 Dez. 2010

FRANKEL, J., STEIN, E.; WEI, S. Trade blocs and currency blocs, in G. de la Deheza et al. (eds.) The Monetary Future of Europe, London: Centre for Economic Policy Research, 1-61, 1993.

. Trading blocs and the Americas: The natural, the unnatural and the supernatural. Journal of Development Economics, v. 47, p. 61-95, 1995.

GIL-PAREJA, S.G., LLORCA-VIVERO, R., MARTINEZ-SERRANO, J. A. "The impact of embassies and consulates on tourism". Tourism Management 28 355-360. 2007.

GLEJSER, H., DRAMAIS, A gravity model of interdependent equations to estimate flow creation and diversion. Journal of Regional Science. Vol. 9, $\mathrm{N}^{\mathrm{o}} 3,1969$.

GOOGLE Earth. Site. Disponível em: <www.google.com/earth>. Acesso em: 11 Set. 2010.

GREENE, W. H.; Econometric Analysis. New Jersey. Pearson Prentice Hall. Sixth Edition. 2008.

GUJARATI, D. N.; Econometria Básica. São Paulo: Pearson Education do Brasil, 2000. Terceira Edição.

HANAFIAH, M. H. M.; HARUN, M. F. M.; JAMALUDDIN, M. R.; Bilateral Trade and Tourism Demand International. World Applied Sciences Journal 10 (Special Issue of Tourism \& Hospitality): 110-114, 2010. 
Determinantes da entrada de turistas estrangeiros nos estados brasileiros no período 2004 a 2008:

uma aborgagem com o modelo gravitacional do turismo

IBGE. Instituto Brasileiro de Economia e Estatística. Portal Oficial. Disponível em <www.ibge.gov.br> Acesso em: 1 Set. 2010.

. (a). Economia do Turismo: Uma Perspectiva Macroeconômica 2007-2010. Estudos e Pesquisas, 2010, Vol. 13.

Economia do Turismo: Uma Perspectiva Macroeconômica 2003-2006. Estudos e Pesquisas, 2009, Vol. 12

INFRAERO. Empresa Brasileira de Infraestrutura Aeroportuária. Portal Oficial. Disponível em <www.infraero.gov.br> Acesso em 10 Dez. 2010

KHADAROO, J., SEETANAH, B. The role of transport infrastructure in international tourism development: A gravity model approach. In: Tourism Management, n. 29, 2008, p. 831-840.

KUME, H., PIANI, G. Fluxos bilaterais de comércio e blocos regionais: uma aplicação do modelo gravitacional. Brasília: IPEA, 2000 (Texto para discussão, $\mathrm{N}^{\mathrm{o}}$. 749).

MADDALA, G.S. "Introdução à Econometria." Rio de Janeiro. Livros Técnicos e Científicos Editora S.A. Terceira Edição. 2003

MATIAS, A. Economic Geography, Gravity and Tourism Trade: Theory, empirical results and policy implications. I Congresso in Tourism Economics, Universitat de les Illes Balears, Palma, 28/29 May 2004.

MATYAS, L. "Proper Econometric Specification of the Gravity Model." The World Economy, 20, 363-68, 1997.

The Gravity Model: Some Econometric Considerations." The World Economy, 21, 397-401, 1998.

MTUR - Ministério do Turismo. Portal Oficial. Disponível em <www. turismo.gov.br> Acesso em: 1 Set. 2010. 
Caracterização e Dimensionamento do Turismo Doméstico no Brasil-2007. Relatório Executivo: Principais Resultados Selecionados. Fundação Instituto de Pesquisas Econômicas, Julho/ 2009. Disponível em: $<$ www.dadosefatos.turismo.gov.br> Acesso em 09 Dez. 2010.

. (a). Estudo da Demanda Turística Internacional (2004 - 2009). Departamento de Estudos e Pesquisas. Brasília, Novembro/2010. Disponível em: <www.dadosefatos.turismo.gov.br>. Acesso em 09 Dez 2010.

NAÇÕES UNIDAS. National Accounts Main Aggregates Database. Portal Oficial. Disponível em: <http://unstats.un.org/unsd/snaama/introduction. asp>. Acesso em: 24 Set. 2010.

OMT / UNWTO. World Tourism Organization. Portal Oficial. Disponível em: <http://unwto.org/en> Acesso em: 14 jan. 2011.

RAIS. Relação Anual de Informações Sociais. Acesso online a base estatística. Disponível em: <http://sgt.caged.gov.br/XOLAPW.dll/pamLoginMTE?lang=0 $>$. Acesso em: 30 Nov. 2010.

SANTOS, G. E. O. Modelo Gravitacional do Turismo: Proposta Teórica e Estudo Empírico dos Fluxos Turísticos no Brasil. Tese de Mestrado, Escola de Comunicações e Artes da Universidade de São Paulo. 2004.

WANG, Z.; WINTERS, L. A. The trading potential of Western Europe. Journal of Economic Integration, v. 7, p. 113-136. 1992.

WOOLDRIDGE, J. M. "Introdução à Econometria: Uma abordagem Moderna”. Cengage Learning. Tradução da Quarta Edição Norte Americana. São Paulo. 2010. 
Determinantes da entrada de turistas estrangeiros nos estados brasileiros no período 2004 a 2008: uma aborgagem com o modelo gravitacional do turismo

\section{APÊNDICES}

Tabela A.1 Ranking de origem (por países) dos fluxos de turistas estrangeiros no Brasil e de destino (por estados) que compõem a amostra de dados.

\begin{tabular}{l|l|l} 
Ranking & Países & Estados \\
$1^{\circ}$ & Argentina & São Paulo \\
$2^{\circ}$ & EUA & Rio de Janeiro \\
$3^{\circ}$ & Itália & Rio Grande do Sul \\
$4^{\circ}$ & Alemanha & Paraná \\
$5^{\circ}$ & Chile & Bahia \\
$6^{\circ}$ & Portugal & Santa Catarina \\
$7^{\circ}$ & Paraguai & Ceará \\
$8^{\circ}$ & França & Pernambuco \\
$9^{\circ}$ & Espanha & Rio Grande do Norte \\
$10^{\circ}$ & Uruguai & Mato Grosso do Sul \\
\hline $11^{\circ}$ & Inglaterra & $\mathrm{X}$ \\
$12^{\circ}$ & Colômbia & $\mathrm{X}$ \\
$13^{\circ}$ & Peru & $\mathrm{X}$ \\
$14^{\circ}$ & Bolívia & $\mathrm{X}$ \\
$15^{\circ}$ & Holanda & $\mathrm{X}$ \\
$16^{\circ}$ & Japão & $\mathrm{X}$ \\
$17^{\circ}$ & México & $\mathrm{X}$ \\
$18^{\circ}$ & Canadá & $\mathrm{X}$ \\
$19^{\circ}$ & Venezuela & $\mathrm{X}$ \\
$20^{\circ}$ & Suíça & \\
\hline
\end{tabular}

Fonte: Elaboração própria.

Nota: Ranking elaborado para o ano de 2008. 